\title{
Dietary overlap between the potential competitors herring, sprat and anchovy in the North Sea
}

\author{
K. Raab ${ }^{1,2}$, L. A. J. Nagelkerke ${ }^{2}$, C. Boerée ${ }^{1}$, A. D. Rijnsdorp ${ }^{1,2}$, A. Temming ${ }^{3}$, \\ M. Dickey-Collas ${ }^{1}$ \\ ${ }^{1}$ Wageningen IMARES, PO Box 68, 1970 AB IJmuiden, The Netherlands \\ ${ }^{2}$ Aquaculture and Fisheries Group, Wageningen University, PO Box 338, 6700 AH Wageningen, The Netherlands \\ ${ }^{3}$ Institut für Hydrobiologie und Fischereiwissenschaft, Olbersweg 24, 22767 Hamburg, Germany
}

\begin{abstract}
European anchovy Engraulis encrasicolus increased its abundance and distribution in the North Sea during the mid-1990s and may consume similar zooplankton to and/or compete with other occupants of the North Sea like herring Clupea harengus and sprat Sprattus sprattus. The diets of adult anchovy, sprat and juvenile herring of comparable sizes, sampled close in time and space, were compared to understand how the 3 species prey on zooplankton and establish whether their diets overlap or not. Anchovy was found to be more generalist, consuming a higher diversity of prey items. Herring was more specialized, with low diversity of food items. Sprat was intermediate between anchovy and herring. The dietary overlap between anchovy and sprat was highest, followed by herring and sprat before anchovy and herring. The mean weight of stomach contents did not differ between species. We conclude that of the 3 species, anchovy is likely to be the least affected by changing plankton communities.
\end{abstract}

KEY WORDS: Stomach analysis $\cdot$ Generalist $\cdot$ Specialist $\cdot$ Planktivorous fish

\section{INTRODUCTION}

The North Sea is a dynamic system and has undergone documented changes in its fish community over the last decades (Daan et al. 2005, Heath 2005, Engelhard et al. 2011). Of interest is the spread of European anchovy Engraulis encrasicolis across the North Sea (Armstrong et al. 1999, Beare et al. 2004a) concurrent with the reported pattern of increase in species of southern geographic affinities (Beare et al. 2004b, Perry et al. 2005, ter Hofstede et al. 2010). The ecological interactions involving anchovy in the North Sea are not well understood, likely due to its past restricted distribution and low abundance; although anchovy were present in the Dutch coastal areas of the Oosterschelde and Wadden Sea (Boddeke \& Vingerhoed 1996), expansions beyond these areas were reported to be unusual (Aurich 1950, Beare et al. 2004a). While the effect of the increased anchovy population on higher trophic levels remains unknown, partially due to a lack of predators' stomach data, its potential trophic interactions with lower trophic levels are starting to be addressed.

European anchovy is a confirmed zooplanktivore in both the North and Baltic Seas (Schaber et al. 2010, Raab et al. 2011), just like in other parts of its distribution, e.g. the Bay of Biscay (Plounevez \& Champalbert 1999), the Mediterranean (Tudela \& Palomera 1995, 1997) and in the Benguela system (van der Lingen et al. 2006). This implies that the North Sea anchovy population may interact with other planktivores such as herring Clupea harengus and sprat Sprattus sprattus. Herring diet is characterised by various copepods (Calanus and Temora 
species), sandeel larvae (Ammodytes spp.), chaetognaths and larvaceans (Hardy 1924, Bainbridge \& Forsyth 1972, Daan et al. 1985, Last 1987). Sprat feed mainly on copepods and less on larger planktonic prey (Ellis \& Nash 1997, Tičina et al. 2000, Casini et al. 2004, Möllmann et al. 2004) and have a very similar diet to North Sea herring (Silva 1973). Anchovy in the North Sea consume mainly copepods and malacostracans, with other items like fish, chaetognaths, larvaceans, gastropods and cephalopods also being found (Raab et al. 2011), and the species also has a varied diet in the western Baltic Sea (Schaber et al. 2010). Clupeids can eat both fish larvae and eggs (e.g. herring: Huse \& Toresen 1996; anchovy: Raab et al. 2011), and anchovy has been observed to be cannibalistic in other systems (Valdés Szeinfeld 1993, Plounevez \& Champalbert 2000, Takasuka et al. 2004), though in some instances this may be due to cod-end feeding (suggested by Borme et al. 2009). The interactions between anchovy, herring and sprat may be manifold. In addition to possible competitive interactions, intra-guild predation (Polis \& Holt 1992) may also occur, and this is likely to be an important factor in the dynamics of small pelagic fish (Valdés Szeinfeld 1991, Irigoien \& de Roos 2011).

Interactions with herring are of particular interest as herring is one of the main commercial species of the North Sea and has suffered low recruitment since 2000, likely due to environmental changes rather than overfishing (Payne et al. 2009, Fässler et al. 2011). North Sea herring has been suggested to have density-dependent growth (Heath et al. 1997, Nash et al. 2009; although see Brunel \& Dickey-Collas 2010). Density dependence may be caused by habitat or food limitation of a population. While singlespecies studies address intra-specific density dependence, inter-specific density dependence may also occur (e.g. as suggested by Casini et al. 2010 between Baltic sprat and herring). The juvenile stage of North Sea herring seems to be the most crucial in determining its growth in later life, thus influencing later reproductive potential since this depends on fish size (Birkeland \& Dayton 2005). Therefore, if food limitation occurs at the juvenile herring stage (when the herring are at a similar size and location as anchovy), then, at a later stage, reproduction and stock productivity of herring could be affected by this inter-specific interaction.

Diet studies of North Sea herring, sprat and anchovy are sparse; therefore, comparing diets reported in the literature is suboptimal, since the zooplankton prey of fish can change across time and space (Young et al. 2009). Studies of North Sea herring diet were carried out prior to the anchovy increase (e.g. Hardy 1924, Last 1989) and also before recent changes in the zooplankton community (Beaugrand 2004). The most recent studies of sprat diet come from the Baltic Sea (e.g. Cardinale et al. 2002, Casini et al. 2004) or other systems (e.g. the Adriatic: Tičina et al. 2000). To understand the inter-specific interactions there is a need to compare these clupeids' diets in the same area and at the same time. Anchovy is perceived as a newcomer and few appropriate information sources exist for this species; however, we use a stomach content dataset from the German Bight (SE North Sea) where all 3 species were sampled at the same time.

The aim of this study was to describe and compare the diets of the co-occurring potential competitors anchovy, juvenile herring and sprat, as well as establish the level of dietary overlap between these species.

\section{MATERIALS AND METHODS}

\section{Data collection}

Anchovy Engraulis encrasicolus, herring Clupea harengus and sprat Sprattus sprattus were sampled in the spring and summer of 2004 as part of the Global Ecosystems Dynamics (GLOBEC, www. globec.org) Germany project. Fish stomachs were extracted onboard and preserved in $4 \%$ buffered formaldehyde. For the analysis presented here, only those individuals caught during the same cruises were kept, in an attempt to ensure that all fish were likely to have encountered the same environmental conditions. Since the main interest was the trophic impact of anchovy, we only analysed and compared fish from the cruises where anchovy were caught, and only at stations close to those where anchovy were caught (east of longitude $7^{\circ} \mathrm{E}$; Fig. 1). Fish diet changes with size (e.g. Casini et al. 2004); thus, only fish of comparable size (12 to $19 \mathrm{~cm}$ ) were analysed. The size ranges of fish were 12 to $13 \mathrm{~cm}$ for sprat (33 adults), 12 to $15 \mathrm{~cm}$ for herring (35 juveniles) and 15 to $19 \mathrm{~cm}$ for anchovy (34 adults). This left a relatively small data set originating from May to August 2004. However, it was likely that these fish encountered similar environmental/prey conditions, as factors such as temporal and spatial variation in prey fields and/or size-dependent changes in diet were minimized.

Stomach contents were weighed and prey items identified to the lowest taxonomic and developmen- 


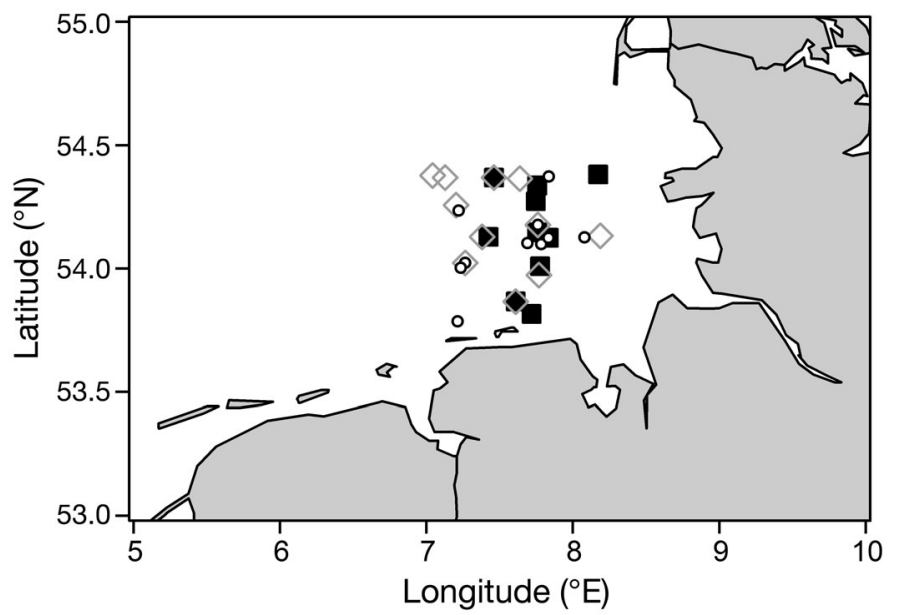

Fig. 1. Sampling stations for anchovy Engraulis encrasicolus $(\square)$, herring Clupea harengus $(\diamond)$ and sprat Sprattus sprattus (o) in the German Bight in late spring/summer 2004

tal stage possible and counted using a binocular microscope when items represented more than half of an identifiable organism. The copepods Paracalanus spp. and Pseudocalanus spp. were recorded jointly (following the example of the Continuous Plankton Recorder Survey; Warner \& Hays 1994) as 'Parapseudocalanus' due to the difficulty in separating these species. An estimate of the volumetric percentage of highly digested items was recorded as these could not be quantified in numbers. We assumed the countable items were also representative for the digested portion of the stomach contents. Counted prey items were grouped into prey categories as often done with stomach analyses (e.g. Möllmann et al. 2004) based on the pooled categorization scheme used in a previous analysis of anchovy diet (Raab et al. 2011). These categories were: Acartia spp., Calanus spp., Centropages spp., chaetognaths, cladocerans, copepods, fish, malacostracans, Oikopleura spp., Parapseudocalanus, Temora spp. and 'other', which included unidentified items. For each stomach, abundances (numbers), proportions (numerical percentages) and presence-absence of each prey category were calculated providing information on different aspects of the diet. Abundances give information on the absolute quantity of items consumed, proportions tell whether the diet is dominated by certain prey items and presence data simply give information on whether prey composition is the same or not. Abundance and wet weight per individual stomach were corrected for fish size by dividing these 2 variables by the cube of individual fish length (as proxy for fish volume). One anchovy was of unknown length; therefore, average length of all other anchovies was used for this scaling.

\section{Diet description}

The 5 most important categories by abundance (scaled by size), proportions per stomach and frequency of occurrence for each species were extracted. To improve our understanding, the abundance data (scaled by size) were back-translated for a hypothetical 'standard fish' of $14 \mathrm{~cm}$ (the average length of all individuals across the species).

Principal components analysis (PCA; described in Legendre \& Legendre 1998) was carried out on stomach contents to visualize the differences between species. Proportions were arcsine-transformed $\left(x^{\prime}=\right.$ $\operatorname{arcsine}[\sqrt{ } x]$ ) before analysis, and PCA was carried out in R (R Development Core Team 2008) using singular value decomposition. Data were centred, and scaling was done only on the abundance data.

\section{Species differences and dietary overlap}

Abundance of prey items per stomach and wet weight of stomach contents (in grams and scaled by fish size) were compared between species using the Kruskal-Wallis test. Dietary overlap between species pairs was calculated for each species pair using the Morisita index of similarity. This index is almost independent of sample size (Wolda 1981, Krebs 1999) and only applicable on abundance data. Another commonly used index of dietary overlap is the percentage overlap, also called Schoener's index and the Renkonen measure (Krebs 1999); thus, for comparability with other studies we include this measure as well. Confidence intervals for the overlap indexes were obtained by bootstrapping, using the accelerated bias-correction method (Efron \& Tibshirani 1993). Fish caught in the same hauls were also compared for diet similarity (percentage overlap and Morisita index) in order to investigate whether these fish, which had more similar feeding conditions, showed the same results as in the overall analysis. However, the number of hauls in which $>1$ of the species was caught was very low: 2 hauls with anchovy-herring, 2 hauls with herring-sprat and 1 haul with anchovy-sprat (the latter with only 1 anchovy in it; see Table 1 for details). Therefore, no further statistical analysis was carried out, and only the range of diet overlap was shown as an indication of variability. 
Table 1. Engraulis encrasicolus, Clupea harengus and Sprattus sprattus. Overview of collected samples' origins per species and per species pair: number of cruises, stations, hauls, and time span (dates and time of day) of stomach collection

\begin{tabular}{|lccccc|}
\hline Species or species pair & Cruises & Stations & Hauls & Dates & Time of day (h) \\
\hline Anchovy & 3 & 10 & 10 & 16 May-10 Aug 2004 & 6:28 (May)-18:36 (Aug) \\
Herring & 2 & 11 & 11 & 15 May-29 Jun 2004 & 08:44 (May)-18:05 (May) \\
Sprat & 3 & 10 & 10 & 16 May-16 Aug 2004 & $08: 50$ (Jul)-16:03 (Aug) \\
Anchovy-Herring & 2 & 2 & 2 & 16 May 2004 & $12: 30$ \\
& & & & 27 Jun 2004 & $09: 00$ \\
Anchovy-Sprat & 1 & 1 & 1 & 1 Jul 2004 & $12: 17$ \\
Herring-Sprat & 2 & 2 & 2 & 27 Jun 2004 & $15: 55$ \\
& & & & 18 May 2004 & $13: 05$ \\
\hline
\end{tabular}

The average diet breadth as used in the above population-level measures can represent many individuals using the whole breadth or it can represent a range of individuals that are specialized on different parts of the range of items represented (Bolnick et al. 2003). Since many ecological mechanisms occur at an individual level, it is important to understand the diet at an individual level as well; therefore, the numerical percentage was calculated for each individual stomach. Numerical percentages were then sorted in decreasing order and averaged across all stomachs of the same species. The resulting average indicates whether the species consists of individual generalists or individual specialists within the sample population (when considering it relative to the other species). In the latter case, few categories suffice to account for a high percentage of stomach contents in each of the stomachs. In the former case, a relatively larger number of prey categories accounts for the same percentage of stomach contents. The Shannon diversity index of each stomach's content was calculated using the diversity function of the vegan library of statistical software R (R Development Core Team 2008) on prey abundances (scaled by fish size). Mean diversity per stomach was then compared between species by using the Kruskal-Wallis test.

\section{RESULTS}

Regardless of measure type (abundance, numerical percentage, or frequency of occurrence), Temora spp. was dominant in the stomachs of both anchovy Engraulis encrasicolus and sprat Sprattus sprattus (Table 2). In an average anchovy stomach, $47 \%$ of items were Temora spp., and $88 \%$ of anchovy stomachs contained this copepod. In the average sprat stomach, $50 \%$ of items were Temora spp., and Temora spp. occurred in $94 \%$ of stomachs. A stan- dard size anchovy $(14 \mathrm{~cm})$ would contain 79 Temora spp., while a standard size sprat would contain 39 Temora spp. items. Centropages spp. were important in abundance and frequency for anchovy. A $14 \mathrm{~cm}$ anchovy would contain 47 Centropages spp., and $76 \%$ of anchovy stomachs contained Centropages spp. Calanus spp. were important prey for herring Clupea harengus. A $14 \mathrm{~cm}$ herring would contain 15 Calanus spp., as well as 15 Temora spp. items. Calanus spp. were more important than Temora spp. by proportions (37 and 33\%, respectively) and frequency of occurrence (71 and $63 \%$, respectively). The PCA showed different patterns according to whether abundance, proportions or presenceabsence was used and explained between 51 and $68 \%$ of the dataset's variance with the first 3 dimensions (Table 3). The number of prey items in each anchovy stomach differed from those of herring and sprat (Fig. 2a). The pattern was driven by the categories 'other', Calanus spp. and Parapseudocalanus, with anchovy varying most along PC1 (representing 'other') and herring and sprat varying most along PC2 (Calanus spp.). Herring was dissimilar from the other 2 species in the proportions of data, with most of the variation explained by the categories Temora spp., Calanus spp. and malacostracans (Fig. 2b). Prey category composition in stomachs was similar in the 3 species, though anchovy appeared to have a broader range of species in its diet (Fig. 2c).

The total number of items per stomach corrected for fish length differed between species (Fig. 3a; Kruskal-Wallis test, $H=13.5 ;$ df $=2 ; \mathrm{p}=0.001$ ). Median abundance per stomach was higher for a $14 \mathrm{~cm}$ anchovy (103 items) than for a sprat (67 items) and higher still for a herring (26 items). Stomach content weight did not differ statistically between the 3 fish species (Fig. 3b; Kruskal-Wallis test, $H=4.5$; $\mathrm{df}=2 ; \mathrm{p}=0.106)$. Median stomach content weight of a $14 \mathrm{~cm}$ fish would be $0.113 \mathrm{~g}$ for anchovy, $0.182 \mathrm{~g}$ for 
Table 2. Engraulis encrasicolus, Clupea harengus and Sprattus sprattus. Prey categories by abundance, proportion and frequency of occurrence (expressed as percentages) in order of decreasing importance for anchovy, herring and sprat. For abundance, the scaled values back-calculated for a $14 \mathrm{~cm}$ fish are given. Parentheses in header line indicate the volumetric percentage of uncountable digested material

\begin{tabular}{|c|c|c|c|c|c|}
\hline Anchovy (+55\%) & Percent & Herring (+90\%) & Percent & Sprat $(+90 \%)$ & Percent \\
\hline \multicolumn{6}{|c|}{ Abundance per stomach for a $14 \mathrm{~cm}$ fish (SD) } \\
\hline Temora spp. & 79 (94) & Calanus spp. & $25(78)$ & Temora spp. & $61(97)$ \\
\hline Centropages spp. & $47(92)$ & Temora spp. & $17(40)$ & Calanus spp. & $17(41)$ \\
\hline Oikopleura spp. & $13(44)$ & Acartia spp. & $5(22)$ & Parapseudocalanus & $15(53)$ \\
\hline Parapseudocalanus & 9 (15) & Malacostracans & $5(8)$ & Cladocerans & $11(35)$ \\
\hline Acartia spp. & $9(17)$ & Parapseudocalanus & $2(5)$ & Centropages spp. & $9(20)$ \\
\hline Other & $7(12)$ & Centropages spp. & $0(1)$ & Acartia spp. & $6(15)$ \\
\hline Malacostracans & $7(9)$ & Copepods & 0 & Fish & $4(16)$ \\
\hline Copepods & $6(13)$ & Oikopleura spp. & 0 & Malacostracans & $2(5)$ \\
\hline Calanus spp. & $6(15)$ & Other & 0 & Oikopleura spp. & $1(3)$ \\
\hline Fish & $5(11)$ & Chaetognaths & 0 & Copepods & $0(1)$ \\
\hline Cladocerans & $3(6)$ & Cladocerans & 0 & Other & $0(1)$ \\
\hline Chaetognaths & $3(13)$ & Fish & 0 & Chaetognaths & 0 \\
\hline \multicolumn{6}{|c|}{ Mean proportion per stomach (SD) } \\
\hline Temora spp. & $47(28)$ & Calanus spp. & $37(40)$ & Temora spp. & $50(34)$ \\
\hline Centropages spp. & $12(21)$ & Temora spp. & $33(39)$ & Cladocerans & $16(27)$ \\
\hline Oikopleura spp. & $9(26)$ & Malacostracans & $16(28)$ & Parapseudocalanus & $9(21)$ \\
\hline Malacostracans & $7(7)$ & Parapseudocalanus & $6(14)$ & Centropages spp. & $8(15)$ \\
\hline Acartia spp. & $5(8)$ & Acartia spp. & $5(18)$ & Calanus spp. & $7(13)$ \\
\hline Other & $5(9)$ & Centropages spp. & $2(7)$ & Acartia spp. & $6(12)$ \\
\hline Parapseudocalanus & $5(6)$ & Copepods & 0 & Fish & $2(8)$ \\
\hline Copepods & $3(5)$ & Oikopleura spp. & 0 & Oikopleura spp. & $2(9)$ \\
\hline Fish & $3(5)$ & Other & 0 & Malacostracans & $1(21)$ \\
\hline Calanus spp. & $2(3)$ & Chaetognaths & 0 & Other & $0(2)$ \\
\hline Chaetognaths & $1(5)$ & Cladocerans & 0 & Copepods & $0(1)$ \\
\hline Cladocerans & $1(1)$ & Fish & 0 & Chaetognaths & 0 \\
\hline \multicolumn{6}{|c|}{ Frequency of occurrence } \\
\hline Temora spp. & 88 & Calanus spp. & 71 & Temora spp. & 94 \\
\hline Malacostracans & 85 & Temora spp. & 63 & Centropages spp. & 58 \\
\hline Centropages spp. & 76 & Malacostracans & 40 & Cladocerans & 49 \\
\hline Other & 76 & Parapseudocalanus & 23 & Acartia spp. & 36 \\
\hline Copepods & 74 & Centropages spp. & 17 & Calanus spp. & 30 \\
\hline Acartia spp. & 68 & Acartia spp. & 11 & Parapseudocalanus & 30 \\
\hline Parapseudocalanus & 68 & Copepods & 3 & Malacostracans & 21 \\
\hline Fish & 62 & Oikopleura spp. & 3 & Oikopleura spp. & 15 \\
\hline Cladocerans & 53 & Other & 3 & Copepods & 12 \\
\hline Calanus spp. & 38 & Chaetognaths & 0 & Fish & 12 \\
\hline Oikopleura spp. & 29 & Cladocerans & 0 & Other & 6 \\
\hline Chaetognaths & 21 & Fish & 0 & Chaetognaths & 0 \\
\hline
\end{tabular}

Table 3. Results of principal components (PC) analysis on abundance (scaled for fish length), proportions and presenceabsence data: proportion of variance explained by the first 3 principal components (expressed as percentage). For each principal component, the prey category representing the highest absolute loading is given

\begin{tabular}{|c|c|c|c|c|c|c|}
\hline & \multicolumn{3}{|c|}{ Variance explained (\%) } & \multicolumn{3}{|c|}{ Categories with highest absolute loading } \\
\hline & Abund. & Prop. & Pres.-Abs. & Abundance & Proportions & Presence-Absence \\
\hline PC1 & 31 & 38 & 38 & Other: -0.47 & Temora spp.: -0.75 & Copepods: -0.38 \\
\hline PC2 & 11 & 19 & 14 & Calanus spp.: -0.60 & Calanus spp.: -0.63 & Calanus spp.: -0.72 \\
\hline PC3 & 9 & 11 & 10 & Parapseudocalanus: -0.51 & Malacostracans: -0.88 & Malacostracans: -0.48 \\
\hline Total & 51 & 68 & 62 & & & \\
\hline
\end{tabular}


herring and $0.082 \mathrm{~g}$ for sprat. The median percentage of highly digested items was $55 \%$ for anchovy and $90 \%$ for both herring and sprat.

Dietary overlap, measured as percent overlap and by the Morisita index, was the highest between anchovy and sprat according to both measures used
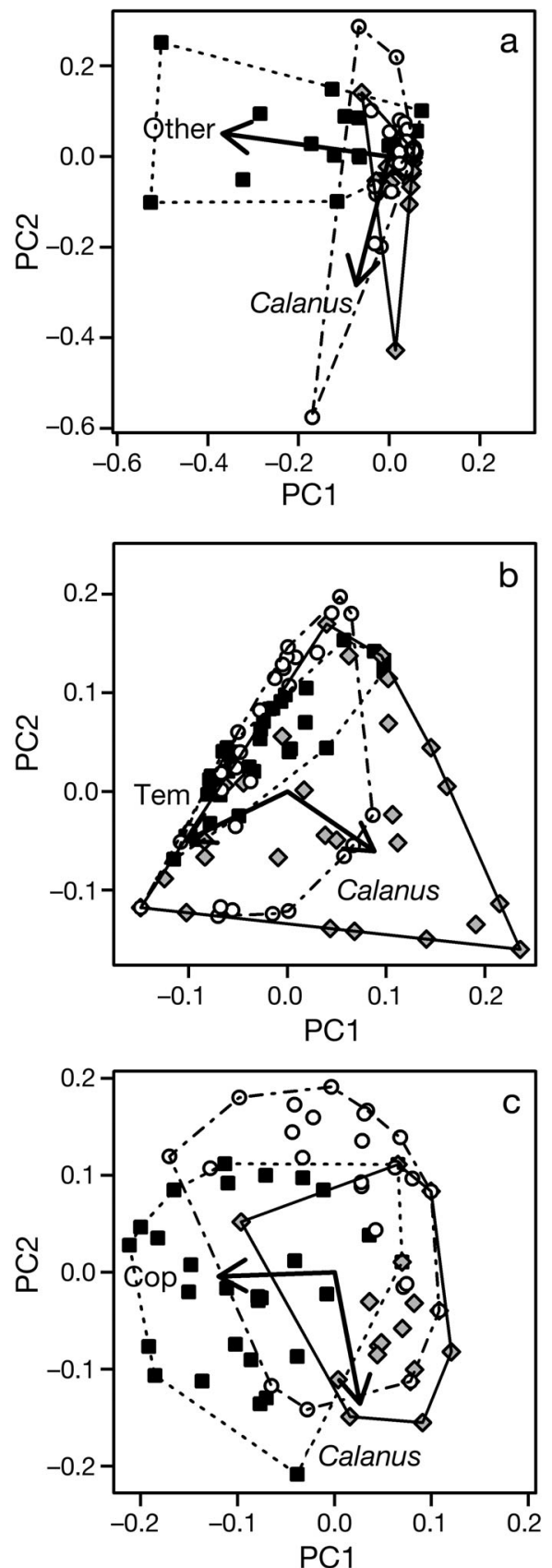

Fig. 2. Engraulis encrasicolus, Clupea harengus and Sprattus sprattus. Results of principal components (PC) analysis on (a) abundance, (b) proportions and (c) presence-absence of prey categories in the stomachs of anchovy (----), herring $(-\diamond-)$ and sprat (--०--). Arrows represent the highest absolute loadings on PC1 and PC2. Tem: Temora spp.; cop: copepods
(67.2\% and 0.883 , respectively) and lowest between anchovy and herring $(47.5 \%$ and 0.540 , respectively). Herring and sprat overlapped by intermediate values $(55.9 \%$ and 0.734 , respectively; Table $4 \mathrm{a})$. The species pairs caught in the same hauls (Table $4 \mathrm{~b}$ ) confirmed that at the within-haul level, anchovyherring overlap (29.0\% and 0.364 , respectively) was also lower than herring-sprat $(42.4 \%$ and 0.525 , respectively). The dietary overlap between anchovy and sprat $(21.7 \%$ and 0.343 , respectively) was lower than that of the other 2 species pairs. Anchovy diet was generally more diverse than that of herring and sprat as measured by the Shannon diversity index. Individual variation among the cumulative abundance curves shows that most anchovy stomachs contained many items, while most herring stomachs contained few items of the same prey category (Fig. 4). Among herring, 2 categories on average made up $>95 \%$ of all prey items, while in sprat and anchovy ca. 3 to 6 categories made up $95 \%$ of prey
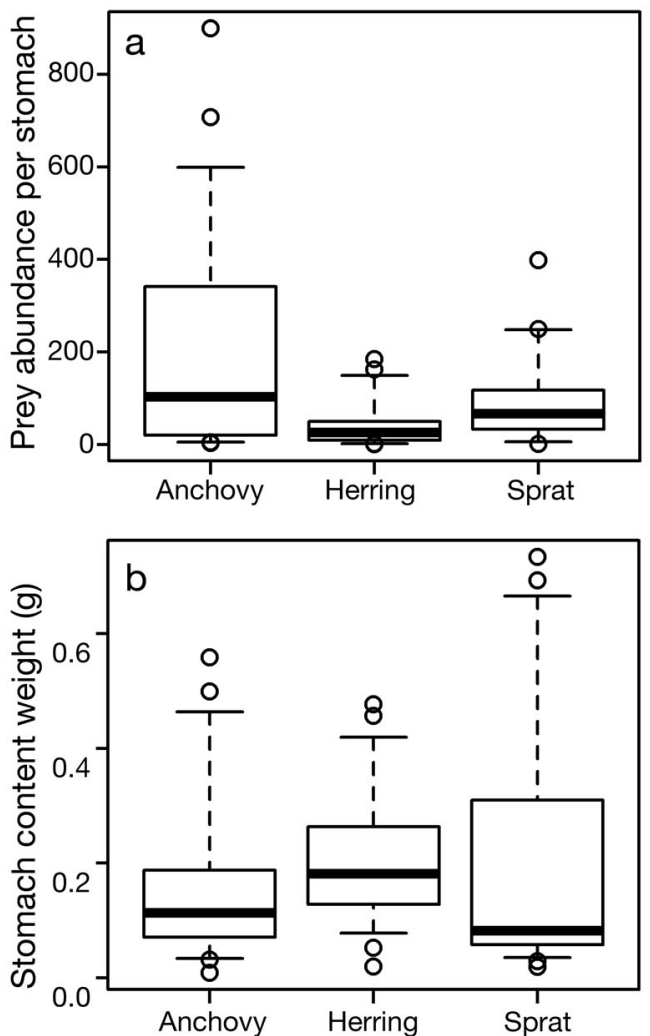

Fig. 3. Engraulis encrasicolus, Clupea harengus and Sprattus sprattus. Boxplot showing (a) median prey abundance per stomach and (b) median wet weight $(\mathrm{g})$ of stomach contents in anchovy, herring and sprat stomachs back-calculated to a $14 \mathrm{~cm}$ standard fish size. Boxes show the medium value (horizontal lines), interquartile range (boxes), 5th and 95th percentiles (whiskers) and outliers (lowest and highest 5 percentiles, circles) 
Table 4. Engraulis encrasicolus, Clupea harengus and Sprattus sprattus. Estimated dietary overlap between the 3 species pairs. Percentage overlap and Morisita's index with (a) $95 \%$ confidence intervals (CI) as estimated by the accelerated biascorrection method or (b) based only on stomachs from the same haul, with the range of resulting dietary overlap values; the number of pairs and stomachs are given.. A: anchovy; H: herring; S: sprat

\begin{tabular}{|llll|}
\hline (a) Species pair & $\begin{array}{l}\text { Percentage overlap } \\
(95 \% \text { CI })\end{array}$ & $\begin{array}{l}\text { Morisita index } \\
(95 \% \text { CI })\end{array}$ \\
\hline Anchovy-Herring & $47.5(42.4-49.1)$ & $0.540(0.518-0.560)$ & \\
Anchovy-Sprat & $67.2(65.9-68.7)$ & $0.883(0.873-0.906)$ & \\
Herring-Sprat & $55.9(50.8-57.5)$ & $0.734(0.654-0.746)$ & No. of pairs (no. of stomachs) \\
(b) Species pair & Percentage overlap (range) & Morisita index (range) & $9(6 \mathrm{~A}+3 \mathrm{H})$ \\
\hline Anchovy-Herring & $29.0(0-70.7)$ & $0.364(0-0.862)$ & $3(1 \mathrm{~A}+3 \mathrm{~S})$ \\
Anchovy-Sprat & $21.7(20.0-25.1)$ & $0.343(0.297-0.385)$ & $36 \mathrm{H}+8 \mathrm{~S})$ \\
Herring-Sprat & $42.4(12.3-73.5)$ & $0.525(0.158-0.896)$ & \\
\hline
\end{tabular}

items. Stomach content diversity after correcting for fish length also differed between the 3 species (Fig. $4 \mathrm{~d}$; Kruskal-Wallis test, $H=25.6$; $\mathrm{df}=2$; $\mathrm{p}<0.001$ ), with anchovy having a higher median diversity index (1.17) than sprat (0.74) and herring (0.47).

Because of the particular interest in possible direct feeding on each other of the 3 clupeids (intraguild
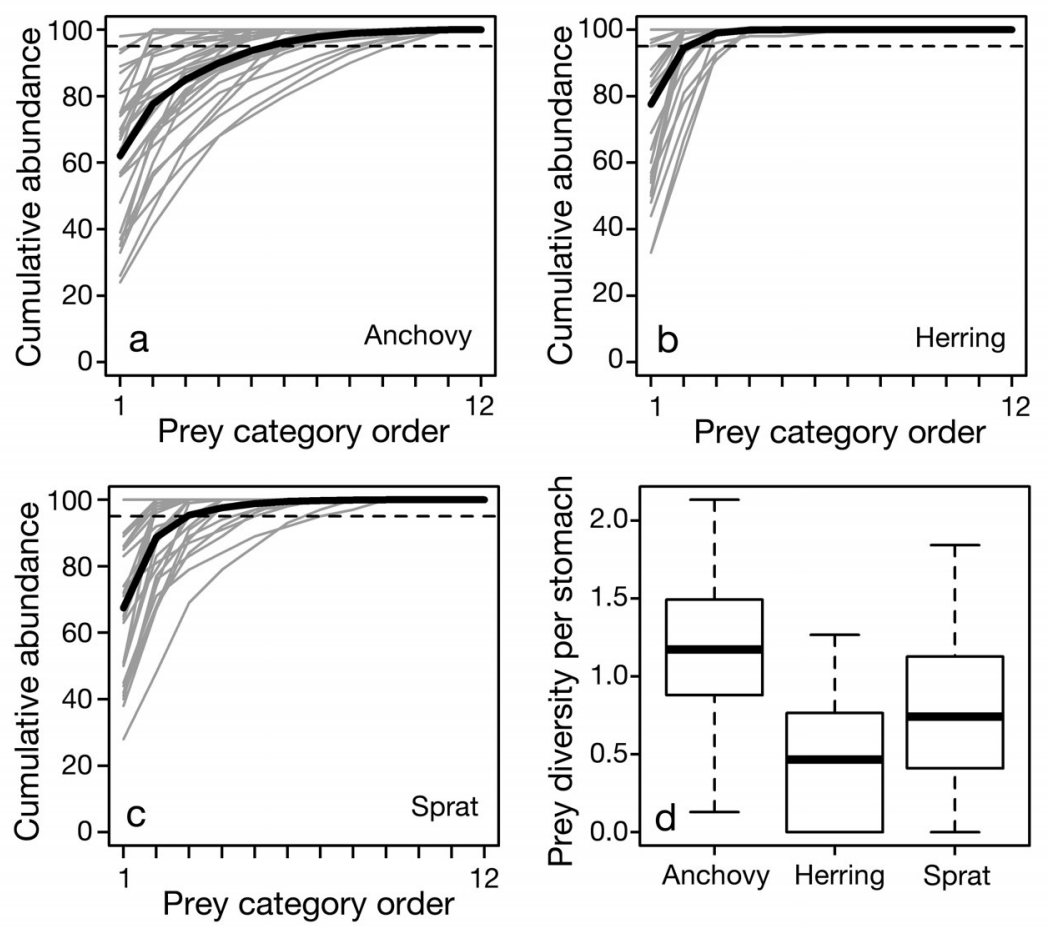

Fig. 4. Engraulis encrasicolus, Clupea harengus and Sprattus sprattus. Diversity in prey items consumed by (a) anchovy, (b) herring and (c) sprat. Cumulative abundance of each individual stomach's prey items (grey) and the average (black) arranged in decreasing order of importance in numerical percentage on the $x$-axis. Thus, the $x$-axis can represent different prey categories for different individuals. The $95 \%$ level is indicated by a horizontal dashed line. (d) Boxplot of mean diversity per stomach (details as in Fig. 3) predation and cannibalism), we explicitly report the 'fish' category (which includes eggs and larvae). Mean abundance of these items per stomach for a $14 \mathrm{~cm}$ fish was 5 for anchovy, 3 for sprat and 0 for herring, and the average percentage was 3 for anchovy, 2 for sprat and 0 for herring. A high number of anchovy stomachs contained fish eggs and larvae (21 out of 34 stomachs), which was higher than for sprat and herring ( 4 out of 33 for sprat; 0 herring out of 35).

\section{DISCUSSION}

The results suggest that anchovy Engraulis encrasicolus is more generalist a planktivore than the other 2 clupeids. Both at the population and at the individual level it consumed a higher number of different prey items than both juvenile herring Clupea harengus and sprat Sprattus sprattus. While anchovy consumed mainly $T e$ mora spp. and a number of other items including Centropages species, malacostracans, appendicularians and other copepods, juvenile herring was more specialised on Calanus and Temora species regardless of which measure of importance was used (abundance, numerical percentage or frequency of occurrence). Sprat too showed Temora to be their most important prey, but other copepods and cladocerans were also important. The anchovy's generalist diet also explains why the category 'other' 
explained much of the variance between stomachs in the multivariate analysis; this was the category that was more abundant and more frequently found in the stomachs of anchovy than in the stomachs of sprat or herring. PCA results from proportions data are more consistent across different categorisation schemes (Raab et al. 2011), suggesting that this may be a more robust measure when semi-arbitrary categorisation schemes are used.

Although there was substantial intra-specific variation in diet, the population level comparison revealed clear differences in diet among the species. Anchovy showed a more diverse diet, whereas sprat and particularly herring showed a more specialised diet. It is well known that predator-prey interactions are affected by the relative size of the predator and prey, but the size dependence may be less prominent in small pelagic fish. It has been found that mean food size (van der Lingen et al. 2009) or wet mass and prey composition (Plounevez \& Champalbert 2000, Schaber et al. 2010) do not relate to the size of adult anchovy, nor was any relationship found between anchovy length and maximum prey size: larvae, juveniles and adults fed on the same plankton size classes (Borme et al. 2009). Therefore, we do not expect the higher diversity observed in the anchovy diet to result from the size distribution of fish in our sample. The diet of adult North Sea sprat also seems relatively independent of fish size; they continue consuming medium-sized copepods when herring, in contrast, changes to increasingly larger items (Last 1987).

Percentage overlap between 0.25 and 0.75 is considered to be intermediate (arbitrarily defined in e.g. Pedersen 1999), and thus all species pairs overlap (except the intra-haul anchovy-sprat comparison) and values fall in the 'intermediate' range. The Morisita index is considered more robust than the percentage overlap measure and shows that anchovy and sprat have relatively high dietary overlap. Anchovy-herring had the lowest dietary overlap, which suggests that of the 3 species pairs, this one has the least potential for dietary competition if they are in the same place. The likelihood of anchovy and sprat interacting seems higher. The order of dietary overlap among species pairs does not completely correspond when using intra-haul comparisons compared to all samples. This is because the anchovy-sprat overlap was calculated based on only 1 anchovy stomach which happened to be the one filled with fish larvae, constituting an outlier to the remaining samples. Discounting this species pair, the order of dietary overlap among species pairs remains the same, with the anchovy-herring still being lower than the herring-sprat overlap. A percentage overlap of $42.3 \%$ between herring and sprat was found in the Baltic Sea, and it was highest in spring and summer (Möllmann et al. 2004). Assuming a similar seasonality in feeding by planktivorous clupeids between the North and Baltic Seas, the overlap found in this study would be relatively high compared to other periods of the year since the analysed stomachs came from late spring/summer sampling events. So the impact on trophic interactions or potential competition by anchovy is dependent on whether the foodlimited period in its life history is during summer or another time. The details of spatial overlap between these species are not known. Anchovy is distributed throughout the North Sea (in Quarter 3, International Bottom Trawl Data) and sprat is in the southern North Sea (ICES 2011), and both spawn in the German Bight, but appear to separate spatially (Alheit 2007). Most North Sea herring spawn in autumn/ winter; therefore, spatial overlap with anchovy and sprat probably occurs when herring is already juvenile and has returned to the eastern North Sea again (ICES 2006). The main feeding time of North Sea herring is from April to June (ICES 2006), and anchovy and sprat spawning activity is also during the sampling time, so if these latter species consume food to cover their increased energetic requirements, the trophic overlap at this time of year is the most relevant to assess. Dietary overlap has been used to suggest trophic competition by several authors (Huse \& Toresen 1996, Möllmann et al. 2004), but the former does not necessarily imply the latter (Holt 1987). For trophic competition to occur, there needs to be trophic niche overlap in time and space combined with insufficient food availability through either low food or high consumption by high numbers of consumers. We assumed that the analysed fish did overlap in time and space, they were selected for that reason, but since the spatial scales of feeding ranges and of plankton prey patchiness are unknown, this work could benefit from a study addressing these issues (see e.g. Young et al. 2009). In addition, we assumed that there is an increase in consumption due to an increase in anchovy population. Trophic niche overlap requires more than just co-occurrence. When species co-occur, the criteria used by each species in food selection must also result in similar food being consumed. Although the characteristics of importance to each species' feeding can predict diet quite well (Sibbing \& Nagelkerke 2001), these are often unknown. Current work on comparing the feeding morphologies of anchovy sprat and herring in the North Sea 
indicates that, although the individual morphological characteristics of the jaw do not differ significantly, the measure of their integrated impact, the filtration area, is significantly larger in anchovy (K. Raab \& L. A. J. Nagelkerke unpubl. data). Anchovy (van der Lingen et al. 2006) and herring (Gibson \& Ezzi 1990) are known to be able to change from filter feeding to particulate feeding depending on feeding conditions, while it has been suggested that sprat, at least in the Baltic, rely more on particulate feeding (Möllmann et al. 2004) but are also capable of filter feeding. Even when there is dietary overlap, behavioural adaptations for resource partitioning can lead to a low potential for competition (even between similar species like Japanese anchovy Engraulis japonicus and Pacific round herring Etrumeus teres; Tanaka et al. 2006). Sampling in the same restricted place/time does not necessarily mean that the sampled fish are using the same exact habitat prior to sampling, but it is more likely than if they are caught at a greater distance in time and space. Young herring are known to prey on fish eggs (Last 1989, Segers et al. 2007), on sprat larvae (Last 1987), on Ammodytes spp. and on herring itself (Hardy 1924), as well as on plaice and cod eggs (Daan et al. 1985, Ellis \& Nash 1997). Sprat also prey on fish eggs (Ellis \& Nash 1997), and anchovy can consume fish larvae too (Plounevez \& Champalbert 2000, van der Lingen et al. 2006). In this study, anchovy had slightly more fish in their stomachs than sprat. No herring had fish larvae in their stomachs. Sprat, anchovy and sardine larvae are found in the German Bight in June and July (Kanstinger \& Peck 2009) and anchovy spawn in May and June. So during the summer they are available to herring, but herring do not consume ichthyoplankton if zooplankton is readily available (Segers et al. 2007). We conclude that direct feeding interactions between all 3 species are possible, but there may be some habitat partitioning which is hidden here by the fact that we specifically chose to analyse the overlapping area. We tried to address this issue by analysing the diets of individual fish caught in the same hauls, but due to very low intra-haul overlap the results are indicative only. However, they confirm the general pattern of anchovy-herring overlap being lower than herring-sprat overlap. No conclusion can be made about anchovy-sprat overlap due to the low sample size $(n=1)$. More detailed and targeted studies comparing the diet of co-occurring and non-co-occurring populations of these species would offer a way to address this question in the future, as has been done for herring and walleye pollock (see Sturdevant et al. 2001).
The anchovy diet, broad as it is, includes the most important prey items of juvenile herring (Calanus and Temora species). If these copepods decline, anchovy can continue feeding on other prey. C. finmarchicus populations are decreasing in the southern North Sea, while Temora species and C. helgolandicus have increased between 1958 and 2003 (Pitois \& Fox 2006). C. finmarchicus is of greater importance by biomass than $C$. helgolandicus in that area, so assuming herring have no preference for either species, the decline would outweigh the increase in its impact on food availability. In the event of a lower abundance of potential prey for herring, it is unclear whether feeding on the second main item (Temora spp.) would be sufficient to maintain herring populations, but, given that this species feeds on many copepods in other systems, it seems likely.

Although anchovy stomachs contained slightly more items by abundance, the 3 species compared contained a similar amount of food by wet weight with some overlap (especially between anchovy and sprat). The clearest difference found was the degree of specialization: highest in juvenile herring and lowest in anchovy. Returning to the idea that anchovy may consume the same food as juvenile herring, it seems that, although diets overlap to some extent, anchovy can consume so many more items that it seems unlikely that there would be any particular trophic effect of the new anchovy population on the herring population. This study forms part of a burgeoning body of literature on North Sea anchovy that seems to indicate that its increase is related to habitat changes (Petitgas et al. 2012) rather than strong changes in trophic interactions. Its existence underlines the value of data collection on non-commercial species which may be required for ecological understanding that may become crucial to implementing an ecosystem approach to fisheries.

Acknowledgements. This research was supported by the EU FP7 grant FACTS (Forage Fish Interactions), grant agreement No. 244966. Thanks to Tobias van Kooten for helpful discussions and to Rémi Vergnon for technical help with R.

\section{LITERATURE CITED}

Alheit J (2007) Climate drives anchovies and sardines into North Sea. GLOBEC Int Newsl 13:77-78

Armstrong MJ, Dickey-Collas M, McAliskey M, McCurdy WJ, Burns CA, Peel JAD (1999) The distribution of anchovy Engraulis encrasicolus in the northern Irish Sea from 1991 to 1999. J Mar Biol Assoc UK 79:955-956

Aurich HJ (1950) Besteht für 1950 Aussicht auf eine Sardellenfischerei in der Nordsee? Fischereiwelt 2:26-28 
Bainbridge V, Forsyth DCT (1972) An ecological survey of a Scottish herring fishery. 5. The plankton of the northwestern North Sea in relation to the physical environment and the distribution of the herring. Bull Mar Ecol 8: 21-52

Beare D, Burns F, Jones E, Peach K and others (2004a) An increase in the abundance of anchovies and sardines in the north-western North Sea since 1995. Glob Change Biol 10:1209-1213

> Beare DJ, Burns F, Greig A, Jones EG and others (2004b) Long-term increases in prevalence of North Sea fishes having southern biogeographic affinities. Mar Ecol Prog Ser 284:269-278

> Beaugrand G (2004) The North Sea regime shift: evidence, causes, mechanisms and consequences. Prog Oceanogr 60:245-262

Birkeland C, Dayton PK (2005) The importance in fishery management of leaving the big ones. Trends Ecol Evol 20:356-358

> Boddeke R, Vingerhoed B (1996) The anchovy returns to the Wadden Sea. ICES J Mar Sci 53:1003-1007

Bolnick DI, Svanbäck R, Fordyce JA, Yang LH, Davis JM, Hulsey CD, Forister ML (2003) The ecology of individuals: incidence and implications of individual specialization. Am Nat 161:1-28

> Borme D, Tirelli V, Brandt S, Fonda Umani S, Arneri E (2009) Diet of Engraulis encrasicolus in the northern Adriatic Sea (Mediterranean): ontogenetic changes and feeding selectivity. Mar Ecol Prog Ser 392:193-209

$>$ Brunel T, Dickey-Collas M (2010) Effects of temperature and population density on von Bertalanffy growth parameters in Atlantic herring: a macro-ecological analysis. Mar Ecol Prog Ser 405:15-28

Cardinale M, Casini M, Arrhenius F (2002) The influence of biotic and abiotic factors on the growth of sprat (Sprattus sprattus) in the Baltic Sea. Aquat Living Resour 15: 273-281

> Casini M, Cardinale M, Arrhenius F (2004) Feeding preferences of herring (Clupea harengus) and sprat (Sprattus sprattus) in the southern Baltic Sea. ICES J Mar Sci 61: 1267-1277

> Casini M, Bartolino V, Molinero JC, Kornilovs G (2010) Linking fisheries, trophic interactions and climate: threshold dynamics drive herring Clupea harengus growth in the central Baltic Sea. Mar Ecol Prog Ser 413:241-252

> Daan N, Gislason H, Pope JG, Rice JC (2005) Changes in the North Sea fish community: evidence of indirect effects of fishing? ICES J Mar Sci 62:177-188

Daan N, Rijnsdorp AD, van Overbeeke GR (1985) Predation by North Sea herring Clupea harengus on eggs of plaice Pleuronectes platessa and cod Gadus morhua. Trans Am Fish Soc 114:499-506

Efron B, Tibshirani RJ (1993) An introduction to the bootstrap. Chapman \& Hall, New York, NY

Ellis T, Nash RDM (1997) Predation by sprat and herring on pelagic fish eggs in a plaice spawning area in the Irish Sea. J Fish Biol 50:1195-1202

Engelhard GH, Ellis JR, Payne MR, ter Hofstede R, Pinnegar JK (2011) Ecotypes as a concept for exploring responses to climate change in fish assemblages. ICES J Mar Sci 68: 580-591

Fässler SMM, Payne MR, Brunel T, Dickey-Collas M (2011) Does larval mortality really influence population productivity? An analysis of North Sea herring time series. Fish Oceanogr 20:530-543
Gibson RN, Ezzi IA (1990) Relative importance of prey size and concentration in determining the feeding behaviour of the herring Clupea harengus. Mar Biol 107:357-362

Hardy AC (1924) The herring in relation to its animate environment, Part 1. The food and feeding habits of the herring with special reference to the east coast of England. Fisheries Investigations, Vol 7. Ministry for Agriculture and Fisheries, London

> Heath MR (2005) Changes in the structure and function of the North Sea fish foodweb, 1973-2000, and the impacts of fishing and climate. ICES J Mar Sci 62:847-868

> Heath M, Scott B, Bryant AD (1997) Modelling the growth of herring from four different stocks in the North Sea. J Sea Res 38:413-436

- Holt RD (1987) On the relation between niche overlap and competition: the effect of incommensurable niche dimensions. Oikos 48:110-114

Huse G, Toresen R (1996) A comparative study of the feeding habits of herring (Clupea harengus, Clupeidae, L.) and capelin (Mallotus villosus, Osmeridae, Müller) in the Barents Sea. Sarsia 81:131-142

ICES (International Council for the Exploration of the Sea) (2006) Report of the study group on recruitment variability in North Sea planktivorous fish (SGRECVAP). ICES CM 2006/LRC:03:1-82

ICES (International Council for the Exploration of the Sea) (2011) Report of the Herring Assessment Working Group South of $62^{\circ} \mathrm{N}$ (HAWG). ICES CM 2011/ACOM:06:1-749

Irigoien X, de Roos A (2011) The role of intraguild predation in the population dynamics of small pelagic fish. Mar Biol 158:1683-1690

Kanstinger P, Peck M (2009) Co-occurrence of European sardine (Sardina pilchardus), anchovy (Engraulis encrasicolus) and sprat (Sprattus sprattus) larvae in southern North Sea habitats: abundance, distribution and biochemical-based condition. Sci Mar 73:141-152

Krebs CJ (1999) Ecological methodology. Addison-Welsey Education Publishers, Menlo Park, CA

Last JM (1987) The food of immature sprat (Sprattus sprattus (L.)) and herring (Clupea harengus L.) in coastal waters of the North Sea. ICES J Mar Sci 44:73-79

Last JM (1989) The food of herring, Clupea harengus, in the North Sea, 1983-1986. J Fish Biol 34:489-501

Legendre P, Legendre L (1998) Numerical ecology. Elsevier Science BV, Amsterdam

Möllmann C, Kornilovs G, Fetter M, Köster FW (2004) Feeding ecology of central Baltic Sea herring and sprat. J Fish Biol 65:1563-1581

Nash RDM, Dickey-Collas M, Kell LT (2009) Stock and recruitment in North Sea herring (Clupea harengus); compensation and depensation in the population dynamics. Fish Res 95:88-97

> Payne MR, Hatfield EMC, Dickey-Collas M, Falkenhaug T and others (2009) Recruitment in a changing environment: the 2000s North Sea herring recruitment failure. ICES J Mar Sci 66:272-277

> Pedersen J (1999) Diet comparison between pelagic and demersal whiting in the North Sea. J Fish Biol 55: 1096-1113

> Perry AL, Low PJ, Ellis JR, Reynolds JD (2005) Climate change and distribution shifts in marine fishes. Science 308:1912-1915

Petitgas P, Alheit J, Peck M, Raab K and others (2012) Anchovy population expansion in the North Sea. Mar Ecol Prog Ser 444:1-13 
Pitois SG, Fox CJ (2006) Long-term changes in zooplankton biomass concentration and mean size over the Northwest European shelf inferred from continuous plankton recorder data. ICES J Mar Sci 63:785-798

Plounevez S, Champalbert G (1999) Feeding behaviour and trophic environment of Engraulis encrasicolus (L.) in the Bay of Biscay. Estuar Coast Shelf Sci 49:177-191

Plounevez S, Champalbert G (2000) Diet, feeding behaviour and trophic activity of the anchovy (Engraulis encrasicolus L.) in the Gulf of Lions (Mediterranean Sea). Oceanol Acta 23:175-192

Polis GA, Holt RD (1992) Intraguild predation: the dynamics of complex trophic interactions. Trends Ecol Evol 7: 151-154

R Development Core Team (2008) R: a language and environment for statistical computing. R Foundation for Statistical Computing, Vienna

Raab K, Nagelkerke LAJ, Boerée C, Rijnsdorp AD, Temming A, Dickey-Collas M (2011) Anchovy Engraulis encrasicolus diet in the North and Baltic Seas. J Sea Res 65: 131-140

Schaber M, Petereit C, Paulsen M (2010) Diet composition and feeding of European anchovy Engraulis encrasicolus in Kiel Bight, western Baltic Sea. J Fish Biol 76: 1856-1862

Segers FHID, Dickey-Collas M, Rijnsdorp AD (2007) Prey selection by North Sea herring (Clupea harengus), with special reference to fish eggs. ICES J Mar Sci 64:60-68

Sibbing FA, Nagelkerke LAJ (2001) Resource partitioning by Lake Tana barbs predicted from fish morphometrics and prey characteristics. Rev Fish Biol Fish 10:393-437

Silva SS (1973) Food and feeding habits of the herring Clupea harengus and the sprat C. sprattus in inshore waters of the west of Scotland. Mar Biol 20:282-290

Sturdevant MV, Brase ALJ, Hulbert LB (2001) Feeding habits, prey fields, and potential competition of youngof-the-year walleye pollock (Theragra chalcogramma) and Pacific herring (Clupea pallasi) in Prince William Sound, Alaska, 1994-1995. Fish Bull 99:482-501

> Valdés Szeinfeld E (1991) Cannibalism and intraguild predation in clupeoids. Mar Ecol Prog Ser 79:17-26

Editorial responsibility: Stylianos Somarakis, Heraklion, Greece
Valdés Szeinfeld E (1993) The energetics and evolution of intraspecific predation (egg cannibalism) in the anchovy Engraulis capensis. Mar Biol 115:301-308

- Takasuka A, Oozeki Y, Kimura R, Kubota H, Aoki I (2004) Growth-selective predation hypothesis revisited for larval anchovy in offshore waters: cannibalism by juveniles versus predation by skipjack tunas. Mar Ecol Prog Ser 278:297-302

> Tanaka H, Aoki I, Ohshimo S (2006) Feeding habits and gill raker morphology of three planktivorous pelagic fish species off the coast of northern and western Kyushu in summer. J Fish Biol 68:1041-1061

ter Hofstede R, Hiddink JG, Rijnsdorp AD (2010) Regional warming changes fish species richness in the eastern North Atlantic Ocean. Mar Ecol Prog Ser 414:1-9

Tičina V, Vidjak O, Kačić I (2000) Feeding of adult sprat, Sprattus sprattus, during spawning season in the Adriatic Sea. Ital J Zool 67:307-311

Tudela S, Palomera I (1995) Diel feeding intensity and daily ration in the anchovy Engraulis encrasicolus in the northwest Mediterranean Sea during the spawning period. Mar Ecol Prog Ser 129:55-61

> Tudela S, Palomera I (1997) Trophic ecology of the European anchovy Engraulis encrasicolus in the Catalan Sea (northwest Mediterranean). Mar Ecol Prog Ser 160:121-134

van der Lingen CD, Hutchings L, Field JG (2006) Comparative trophodynamics of anchovy Engraulis encrasicolus and sardine Sardinops sagax in the southern Benguela: Are species alternations between small pelagic fish trophodynamically mediated? Afr J Mar Sci 28:465-477

van der Lingen CD, Bertrand A, Bode A, Brodeur R and others (2009) Trophic dynamics. In: Checkley DM, Alheit J, Oozeki Y, Roy C (eds) Climate change and small pelagic fish. Cambridge University Press, Cambridge, p 112-157

Warner AJ, Hays GC (1994) Sampling by the continuous plankton recorder survey. Prog Oceanogr 34:237-256

> Wolda H (1981) Similarity indexes, sample-size and diversity. Oecologia 50:296-302

Young KV, Dower JF, Pepin P (2009) A hierarchical analysis of the spatial distribution of larval fish prey. J Plankton Res 31:687-700

Submitted: November 25, 2011; Accepted: June 29, 2012 Proofs received from author(s): November 13, 2012 